\title{
Production of TRPV2-targeting functional antibody ameliorating dilated cardiomyopathy and muscular dystrophy in animal models
}

\author{
Yuko Iwata $^{1} \cdot$ Shigeo Wakabayashi ${ }^{2} \cdot$ Shin Ito $^{1} \cdot$ Masafumi Kitakaze ${ }^{1}$
}

Received: 30 August 2019 / Revised: 18 December 2019 / Accepted: 18 December 2019 / Published online: 2 January 2020

(c) The Author(s), under exclusive licence to United States and Canadian Academy of Pathology 2020

\begin{abstract}
Abnormal $\mathrm{Ca}^{2+}$ handling is essential in the pathophysiology of degenerative muscle disorders, such as dilated cardiomyopathy (DCM) and muscular dystrophy (MD). Transient receptor potential cation channel, subfamily V, member 2 (TRPV2) is a candidate for $\mathrm{Ca}^{2+}$ entry and a potential therapeutic target for degenerative muscle disorders, there are few specific inhibitors for TRPV2. In this study, we produced a monoclonal antibody (designated mAb88-2) and two polyclonal antibodies (pAb591 and pAb592) that selectively recognize TRPV2 from the outside of cells and interact with the turret region of the pore-forming outer gate. These antibodies inhibited $\mathrm{Ca}^{2+}$ influx via TRPV2 in cultured cells and substantially reduced TRPV2 in the plasma membrane via cellular internalization. We evaluated the therapeutic efficacy of the functional antibody in $\delta$-sarcoglycan-deficient hamster (J2N-k) models of DCM and MD and in the 4C30 DCM model of murine heart failure. The intraperitoneal administration of the functional antibody $(0.5 \mathrm{mg} / \mathrm{kg}$ ) for 2 weeks (once a week) prevented the progression of cardiac dysfunction, as evaluated by echocardiography and histological staining, and improved the abnormal $\mathrm{Ca}^{2+}$ handling (high diastolic $\mathrm{Ca}^{2+}$ level and small $\mathrm{Ca}^{2+}$ transient peak) in cardiomyocytes isolated from J2N-k hamsters and prevented skeletal muscle damage. Further, the antibody effectively prevented heart failure in the 4C30 mouse model with end-stage DCM. Interestingly, endogenous TRPV2 that accumulated in the cardiac and skeletal muscle sarcolemma disappeared upon antibody administration. Thus, the newly produced antibodies are capable of ameliorating DCM and MD by promoting the cellular internalization of TRPV2; antibodies specific to human TRPV2 may substantially improve the treatment of patients with degenerative muscle diseases.
\end{abstract}

\section{Introduction}

Dilated cardiomyopathy (DCM) is a severe disorder defined by ventricular dilation and cardiac dysfunction [1-3]. DCM is a major risk factor for heart failure and is often associated with severe arrhythmia, indicating the pathological involvement of the cardiac conduction system. Although DCM often develops as a result of hypertension, inflammation, infection, valve disease, and metabolic and toxic effects of

Supplementary information The online version of this article (https:// doi.org/10.1038/s41374-019-0363-1) contains supplementary material, which is available to authorized users.

Yuko Iwata

yukoiwat@ncvc.go.jp

1 Department of Clinical Research and Development, National Cerebral and Cardiovascular Center, Suita, Japan

2 Department of Pharmacology, Osaka Medical Collage, Takatsuki, Osaka, Japan medications, 30-48\% of cases are caused by mutations [4]. The standard therapy for patients with DCM involves angiotensin-converting enzyme inhibitors or angiotensin receptor blockers as well as beta-blockers, aldosterone antagonists, and, in selected cases, vasodilators [5-7]. However, treatment options for patients with refractory heart failure are limited and patients may require left ventricular assist devices or heart transplantation $[5,6]$.

DCM is also associated with mutations in various genes, including genes encoding sarcomeric (e.g., titin and troponin T), extracellular matrix (e.g., laminin 2 and laminin 4), and nuclear membrane proteins (e.g., lamin $\mathrm{A} / \mathrm{C}$ and emerin). The most frequent mutations reported in DCM are in genes encoding cytoskeletal proteins, including components of the dystrophin-glycoprotein complex (DGC) [8, 9]. Patients with DCM caused by mutations, especially mutations in DGC components, also develop muscular dystrophy (MD) [10]. DGC defects could disrupt membrane integrity or stability during muscle contraction/relaxation and prevent myocyte survival. The enhanced susceptibility to muscle damage is observed in dystrophic animals, such as 
dystrophin-deficient $\mathrm{mdx}$ mice or $\delta$-SG-deficient $\mathrm{J} 2 \mathrm{~N}-\mathrm{k}$ hamsters, which are models of Duchenne MD or human autosomal recessive limbgirdle MD (LGMD2F) in humans, respectively, owing to the similarities in symptoms [10, 11]. Thus, there are likely common molecular mechanisms underlying DCM and MD.

We have previously shown that myotubes from $\delta$-SGdeficient hamster skeletal muscles are highly susceptible to mechanical stretch and show enhanced $\mathrm{Ca}^{2+}$-influx via stretch-activated nonselective $\mathrm{Ca}^{2+}$ channels $[12,13]$. Transient receptor potential cation channel, subfamily $\mathrm{V}$, member 2 (TRPV2) is a major candidate for $\mathrm{Ca}^{2+}$-entry; it is related to abnormal $\mathrm{Ca}^{2+}$ handling in muscular degeneration [14]. Furthermore, TRPV2 exacerbates the development of DCM based on the following observations: (1) cardiac-specific TRPV2 overexpression results in DCM [14], (2) TRPV2 expression in the cardiac sarcolemma is increased in DCM models, such as J2N-k hamsters, and a mouse model (4C30), and in patients with idiopathic cardiomyopathy or heart failure [15], and (3) the inhibition of TRPV2 activity by several strategies effectively prevents cardiomyopathy as well as MD [15-17]. An antiallergic agent, tranilast, and recently identified potent TRPV2 inhibitors inhibit $\mathrm{Ca}^{2+}$ entry through TRPV2 and ameliorate muscle degeneration [15, 17]. However, since these drugs have high effective doses $(10-100 \mu \mathrm{M})$ and other effects [18, 19], new specific TRPV2 inhibitors, such as neutralizing antibodies, are needed to confirm whether TRPV2 inhibition is promising for the treatment of degenerative muscle diseases.

In this study, we successfully produced several neutralizing antibodies against TRPV2. These antibodies interact with the extracellular domain of TRPV2 and inhibit $\mathrm{Ca}^{2+}$ influx. The effects of these antibodies were evaluated using $\delta$-sarcoglycan-deficient hamsters (J2N-k) and 4C30 mouse models of end-stage DCM.

\section{Materials and methods}

\section{Materials}

2-APB (2-Aminoethoxydiphenyl borate) was purchased from Sigma Chemical (St. Louis. MO). Tranilast was obtained from Kissei Pharmaceutical (Matsumoto City, Nagano, Japan). Fura-2-acetoxymethyl ester (AM) from Dojindo Lab (Kumamoto, Japan), Indo-1-AM from Invitrogen (Carlsbad, CA). The other chemicals were the highest purity available.

\section{Animal experiments}

$\delta$-sarcoglycan-deficient cardiomyopathic hamsters $\mathrm{J} 2 \mathrm{~N}-\mathrm{k}$ and age-matched normal controls J2N-n were purchased from Japan SLC. The J2N-n had the same genetic background as the $\mathrm{J} 2 \mathrm{~N}-\mathrm{k}$, except for the difference of a genetic locus for cardiomyopathy. DCM mice (4C30) that overexpresses $\beta$-galactoside $\alpha$-2,3-sialytransferase II were described previously [20]. Male animals were used for the following experiments. For antibody administration, monoclonal antibody mAb88-2 or control IgG (mouse IgG2a functional grade clone 6H3 MBL M076-3M2) was intraperitoneally injected to J2N-k hamsters with 9 weeks of age once a week at a dose of $0.5 \mathrm{mg} / \mathrm{kg}$ or to $4 \mathrm{C} 30$ mice with 25 weeks of age once a week at a dose of $0.25 \mathrm{mg} / \mathrm{kg}$ or $0.5 \mathrm{mg} / \mathrm{kg}$. After administration for 2 weeks, animals were subjected to measurement of serum creatine phosphokinase (CK) level, echocardiography, and histochemical analysis. Histochemistry of muscles was performed as described previously [21]. We performed the control experiment for safety by peritoneal injections of TRPV2 antibody (mAb88-2) $(0.5$ and $2 \mathrm{mg} / \mathrm{kg}$ ) to male and female wild-type BL6 mice once a week for 4 weeks, $n=5$ each group. The body weight and food consumption were measured periodically, 7 days after the final administration, an autopsy was performed, and blood and organs were collected for hematological examination, serum biochemistry examination, and histological observation. Effective doses of the functional antibody in vivo were estimated as the time-dependent decay of the remaining activity of the antibody in the serum. All animal experiments were performed according to the Guidelines for Animal Experimentation at the National Cerebral and Cardiovascular Center Research Institute.

\section{Histology}

Cardiac and skeletal muscles were fixed in phosphate buffer saline (PBS) containing 10\% formalin and embedded in paraffin. Serial sections $(5 \mu \mathrm{m})$ were stained with hematoxylin and eosin and Masson's trichrome for morphological analysis. Stained serial sections were viewed under a light microscope (OLYMPUS BX41) and images were analyzed using a computer-assisted imaging system (FLOVEL Filing System) by investigators blinded to the genotypes. Images were acquired using a digital camera (Olympus FX380) equipped with image filing software (Flovel FLVFS-LS, Tokyo, Japan). Fibrosis was assessed by measuring the Masson's trichrome-positive area. Briefly, color images were converted to binary images by setting a threshold so only blue-stained fibrotic areas were detected. These areas were summed and reported as a percentage of the total.

\section{Measurement of blood pressure (BP)}

Arterial BP was measured noninvasively in conscious mice by the plethysmographic tail-cuff method (model 
BP-98A-L; Softron, Tokyo, Japan). 4C30 mice with 26 and 27 weeks of age were warmed for more than 5 min at $37^{\circ} \mathrm{C}$ in the cylindrical thermostat before and during the $\mathrm{BP}$ measurement. BP was measured in 2-min intervals and the mean of five steady state measurements was accepted as the true BP in each mouse. Heart rates of each mouse was simultaneously measured as BP measurement.

\section{Echocardiography}

Cardiac function was evaluated by two-dimensional echocardiography using a Visual Sonics Vevo 2100 Ultrasound (Visual Sonics, Toronto, Ontario, Canada) on $1.5 \%$ isoflurane-anesthetized hamsters or mice as described previously [22]. The left ventricular fractional shortening (FS) was calculated according to the following formula: FS (\%) $=[($ LVIDd - LVIDs $) /$ LVIDd $] \times 100$, where LVIDd and LVIDs are the left ventricular internal diastolic and systolic dimensions $(\mathrm{mm})$, respectively.

\section{Molecular biology}

All plasmid constructions for TRPV2, TRPV1, and TRPC1 were essentially carried out by PCR-based strategy using the full-length mouse TRPV2 (mTRPV2), human TRPV2 (hTRPV2), hamster TRPV2 (hmTRPV2), canine TRPV2, human TRPV1, human TRPC1 cDNA cloned into the pIRES expression vector (Invitrogen, Carlsbad, CA) as described previously [17].

\section{Antibody production}

Autoimmune-diseased mice were immunized with HEK293 cells expressing the full-length mTRPV2 and produced monoclonal antibodies as described previously [23]. Briefly, $25 \mu \mathrm{l}$ of PBS and complete Freund's adjuvant $(1: 1)$ was injected into the mice, and mTRPV2 expressing HEK293 cells $\left(2 \times 10^{7}\right.$ in $400 \mu$ of PBS) were then injected into mice at 1,4 , and 7 days. Three days after the final injection, lymph-node cells were removed from immunized mice and fused with P3U1 myeloma cells at a ratio of 5 to 1 by polyethyleneglycol-400 procedure. Hybridoma supernatants were screened on HEK293 cells expressing mTRPV2 by flow cytometric analysis and then by high throughput TRPV2 $\mathrm{Ca}^{2+}$ measurement as described previously [17]. After cloning the hybridomas suitable for the purpose, the monoclonal antibodies were purified by protein G Sepharose column chromatography.

Alternatively, several peptides corresponding the extracellular region of mTRPV2 were synthesized (Fig. S1) and immunized to rabbits, hens and mice, and the efficacy of antiserum were checked by immunocytochemistry, immunoblot and activity measurement using HEK293 cells expressing mTRPV2. For epitope mapping of obtained antibodies, 15 peptides (8-mer each) spanning amino acid (aa) 568-589 of pre pore region were synthesized and subjected to binding activity assay using the peptide dot assay.

\section{Cardiomyocyte isolation}

Single-ventricular myocytes were freshly isolated from normal or J2N-k hamsters' hearts using standard enzymatic techniques as described previously [15]. Briefly, hearts were rapidly removed from pentobarbital $(50 \mathrm{mg} / \mathrm{kg}$ weight)anesthetized hamsters and perfused in a Langendorf perfusion system with an enzyme solution containing $1 \mathrm{mg} / \mathrm{ml}$ Type 2 collagenase (Worthington Biochemical Corp.), 0.05 $\mathrm{mg} / \mathrm{ml}$ protease (Sigma), and $0.05 \mathrm{mg} / \mathrm{ml}$ trypsin (Sigma) at $37^{\circ} \mathrm{C}$. Ventricles were separated, cut into small pieces, and further digested by incubation with the enzyme solution described above plus $2 \mathrm{mg} / \mathrm{ml} \mathrm{BSA}$ and $0.5 \mathrm{mM} \mathrm{CaCl} 2$ for several minutes at $37{ }^{\circ} \mathrm{C}$. The cell suspension was filtered ( $0.1 \mathrm{mM}$ mesh), subjected to two rounds of centrifugation (400 rpm, $3 \mathrm{~min}$ ) with gradually increasing $\mathrm{CaCl}_{2}$ (1 and $1.5 \mathrm{mM}$ ), and finally resuspended in Tyrode solution containing (mM): $\mathrm{NaCl}, 137 ; \mathrm{KCl}, 5.4$; HEPES, $10 ; \mathrm{MgCl}_{2}, 1$; $\mathrm{CaCl}_{2}, 1.5$; and glucose, 10 (adjusted to $\mathrm{pH} 7.4$ with $\mathrm{NaOH})$. Myocytes were immediately plated onto laminin $(0.1 \mathrm{mg} / \mathrm{ml})$-coated glass coverslips and allowed to attach by incubation at $37^{\circ} \mathrm{C}$. Isolated myocytes, with a rodshaped appearance, clear striations, no membrane blebs, and no spontaneous contractions, were used for experimentation within $8 \mathrm{~h}$.

\section{Cell culture}

Culture of myotubes was performed using muscles from normal or J2N-k hamsters by enzymatic dissociation essentially as described previously [24]. Briefly, we prepared satellite cells from the gastrocnemius muscle of hamsters using an enzyme cocktail containing $0.5 \mathrm{mM}$ $\mathrm{CaCl}_{2}$ for cell dissociation. After enrichment of the myoblasts by several preplatings, cells were placed on the culture dishes; 2 days later, the culture medium was switched to DMEM containing $2 \%$ horse serum to induce myotube formation. Two to four days after the start of fusion, the generated myotubes were analyzed. HEK293 cells and its corresponding transfectants were maintained in DMEM containing $25 \mathrm{mM} \mathrm{NaHCO}_{3}$ and supplemented with $7.5 \%(\mathrm{v} / \mathrm{v})$ fetal calf serum. cDNAs were transfected into HEK293 cells with Lipofectamine 3000 (Invitrogen Carlsbad, CA) and stable clones were isolated after selection with puromycin (Nakarai Tesuque). 


\section{Measurement of intracellular $\mathrm{Ca}^{2+}$-transient and single-cell contractility in cardiomyocytes}

The isolated cardiomyocytes were loaded for $10 \mathrm{~min}$ with $10 \mu \mathrm{M}$ indo-1 AM, and then placed on the stage of an inverted microscope (IX 71, Olympus) adapted for epifluorescence. Cells were continuously superfused with Tyrode solution at a constant flow of $1 \mathrm{ml} / \mathrm{min}$. Myocyte contraction was produced by field stimulation at $1 \mathrm{~Hz}$ with two platinum electrodes (square waves, 2-ms duration, and $20 \%$ above threshold), which were connected to a stimulator (SEN-8203, Nihon Kohden) with a bath drive amplifier (Nihon Kohden). The excitation light was centered at $340 \mathrm{~nm}$, and emission was collected at 405 and $480 \mathrm{~nm}$, with an 8 ms-temporal resolution, using a cooled fast CCD camera (EMCCD, Hamamatsu photonics K.K., Japan) as described previously [21]. The data were stored directly on the hard drive and further processed with AQUACOSMOS software (Hamamatsu photonics).

\section{Immunocytochemistry}

Cultured cells or isolated cells were stained with each antibody (dilution, 1:50) and secondary Alexa-coupled antibody (1:500) or rhodamine WGA (1:500) at the nonfix condition or after fix with 4\% PFA at RT for $5 \mathrm{~min}$. In some experiments, cells were stained with antibodies after fixed with $4 \%$ PFA for $15 \mathrm{~min}$ at RT and permeabilized with $0.1 \%$ TritonX-100 for $1 \mathrm{~min}$ at RT. Signals were observed by confocal microscopy with an Olympus Fluoview FV1000 confocal microscope. A frozen section $(\sim 5 \mu \mathrm{M})$ of muscles was stained with antibodies as described previously [15]. Anti-flag Ab, anti-HA, and rabbit antiTRPV2 antibody against C-terminal cytoplasmic domain (anti-TRPV2) were used as described previously [14-16].

\section{Intracellular $\mathrm{Ca}^{2+}$ measurement}

The measurement of the intracellular $\mathrm{Ca}^{2+}$ concentration was performed by a ratiometric fluorescence method essentially as described previously [15, 17]. Briefly, HEK293 cells and myotubes were loaded with $4 \mu \mathrm{M}$ fura-2 acetoxymethyl ester (fura-2/AM) for $30 \mathrm{~min}$ at $37^{\circ} \mathrm{C}$, and maintained in balanced salt solution (BSS) $(146 \mathrm{mM} \mathrm{NaCl}$, $4 \mathrm{mM} \mathrm{KCl}, 2 \mathrm{mM} \mathrm{MgCl} 2,0.5 \mathrm{mM} \mathrm{CaCl}, 10 \mathrm{mM}$ glucose, $0.1 \%$ bovine serum albumin, and $10 \mathrm{mM}$ HEPES/Tris, $\mathrm{pH}$ 7.4); fura-2 fluorescence was measured using a fluorescence image processor (Aquacosmos, Hamamatsu Photonics). Agonist stimulation or mechanical stretch was performed in BSS containing 2 or $5 \mathrm{mM} \mathrm{CaCl}_{2}$. Stimulation with 2-APB was performed in BSS containing 2 or $5 \mathrm{mM} \mathrm{CaCl}_{2}$ and adjusted to the lower $\mathrm{pH}$ ( $\mathrm{pH}$ 6.5). In the case of screening of inhibitable antibody, cells were plated on 96-well and fura-2 fluorescence ratio at 340/380 was monitored using a POLAR star Omega microplate reader (BMG Labtech, Germany). All $\mathrm{Ca}^{2+}$ measurements were carried out at room temperature.

\section{Application of cell-stretch to myotubes}

Mechanical stretching was applied to myotubes using a chamber. The silicon chamber with a transparent bottom $200 \mu \mathrm{M}$ thick was attached to a stretching apparatus that was driven by a computer-controlled stepping motor. Cells were allowed to attach to the chamber bottom for the indicated times, and monoaxial sinusoidal stretching was applied to the silicon chamber at a constant strength from 5 to $20 \%$ elongation at $1 \mathrm{~Hz}$. The relative elongation of the silicone membrane was uniform across the whole membrane area. Stretching experiments were performed at $25 \pm 1{ }^{\circ} \mathrm{C}$.

\section{Enzyme assay and other procedures}

CK activity in the medium was determined using an in vitro colorimetric assay kit (CK Test Kit, Wako Pure Chem. Co., Osaka, Japan) according to the protocol provided by the manufacturer. Quantitative immunoblotting analysis and immunocytochemistry were performed as described previously $[12,24]$. Protein concentration was measured using a bicinchoninic acid assay system (Pierce Chemical Co., Rockford, IL) with bovine serum albumin as a standard.

\section{Statistics}

Unless otherwise stated, data were represented as means \pm S.D. of at least three determinations.

All histochemical and physiological analysis was done by investigators blinded to the treatments. We used unpaired Student's $t$ test and one-way ANOVA followed by Dunnett's test for statistical analysis. $p<0.05$ indicates statistical significance.

\section{Results}

\section{Production of neutralizing antibodies against TRPV2}

We produced antibodies that specifically inhibit TRPV2 activity from the outside of cells using two strategies. (1) mTRPV2 without tags (see Fig. S1 for the secondary structure) was stably transfected into HEK293 cells, and mice were immunized with cells overexpressing mTRPV2. The resulting hybridoma supernatants were evaluated for the inhibition of the agonist (2-APB)-induced increase in cytosolic $\mathrm{Ca}^{2+}$ by high throughput screening, following our previously described methods [17]. A monoclonal antibody 


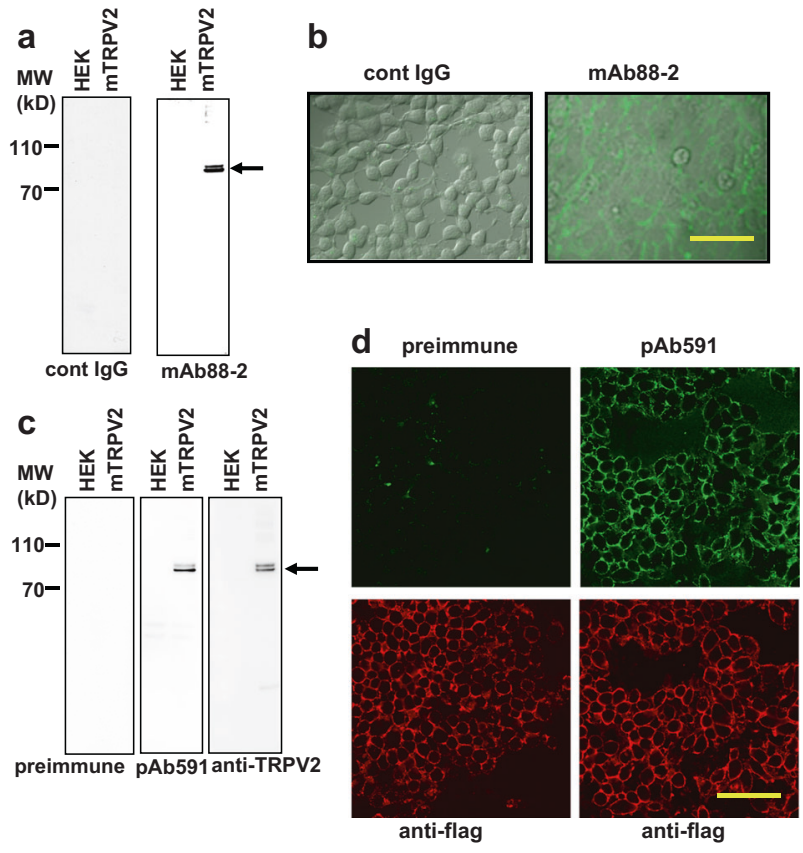

Fig. 1 Produced monoclonal and polyclonal antibodies recognize TRPV2 from the extracellular side. a Equal amounts $(10 \mu \mathrm{g})$ of lysates from HEK293 cells (HEK) or HEK293 cells stably expressing mouse TRPV2 (mTRPV2) were subjected to immunoblot analysis using control IgG (dilution, 1:500) or monoclonal antibody mAb88-2 (1:500). b Live HEK293 cells stably expressing mTRPV2 were stained with mAb88-2 or control IgG followed by Alexa488-conjugated secondary anti-mouse antibody. Scale bar: $50 \mu \mathrm{M}$. c Immunoblot analysis with preimmune rabbit serum or polyclonal antibody pAb591(1:500) or polyclonal TRPV2 antibody (anti-TRPV2) (1:500) on HEK293 or mTRPV2-transfectants. d Cells expressing mTRPV2 extracellularly tagged with flag were fixed and incubated with preimmune serum plus anti-flag antibody, or pAb591 plus anti-flag antibody without cell permeabilization, and then cells were stained with the mixture of Alexa488 or Alexa546-conjugated antibodies. Scale bar: $50 \mu \mathrm{M}$.

designated mAb88-2 was successfully obtained. (2) Eight peptides corresponding to the extracellular loops of mTRPV2 (Fig. S1) were synthesized and used to immunize various hosts (rabbit, rat, mouse, and hen). Several antibodies recognizing TRPV2 (Fig. S1B, C) were obtained. Among these, two polyclonal antibodies, pAb591 and pAb592, obtained from two rabbits were able to inhibit TRPV2 activity from the outside of cells.

These antibodies specifically recognized mTRPV2 expressing cells (Fig. 1a, c). They were able to recognize mTRPV2 expressed in the plasma membranes from the outside of live cells (Fig. 1b) and nonpermeabilized fixed cells (Fig. 1d). The antibodies mAb88-2 and pAb591 inhibited the agonist (2-APB)-induced increase in cytosolic $\mathrm{Ca}^{2+}$, indicating TRPV2 activity, as measured using a plate reader (Fig. 2a). Half maximal inhibitory concentrations of pAb591 and mAb88-2 for the $\mathrm{Ca}^{2+}$ increase induced by $0.5 \mathrm{mM}$ 2-APB were 5 and $1 \mu \mathrm{g} / \mathrm{ml}$, respectively (Figs. $2 \mathrm{~b}$ and $\mathrm{S} 2 \mathrm{~A})$. Figure $2 \mathrm{c}$ shows the fluorescence ratio imaging results. In HEK293 cells expressing mTRPV2, 2-APB induced a substantial increase in the cytosolic $\mathrm{Ca}^{2+}$ concentration, and this increase was efficiently inhibited by the pAb591 antibody. Another TRPV2 stimulant, high temperature $\left(>52{ }^{\circ} \mathrm{C}\right)$, also induced a $\mathrm{Ca}^{2+}$ increase, which was inhibited by pAb591 (Fig. 2c). Thus, we successfully obtained neutralizing antibodies that efficiently inhibit TRPV2 activity from the outside of cells.

\section{Epitope mapping and specificity of antibodies}

Epitope mapping was performed using synthesized peptides. Two peptides near the pore region within the third extracellular loop were added to the nitrocellulose membrane: peptide 6 (aa 568-589) and peptide 5 (aa 551-566) (see Fig. S1A for positions of peptides). Surprisingly, in addition to pAb591 and pAb592, mAb88-2 also recognized peptide 6, which was used for production of polyclonal antibodies, but not peptide 5 (Fig. 3a). We synthesized 15 peptides (each 8mer) and determined a precise epitope for these antibodies. The sequence GQEEEPVPY was a common epitope against these antibodies (Fig. 3b). This sequence is specific for TRPV2 among the TRPV family (Fig. 3c). Based on the structure of the full-length rat TRPV2 channel determined by cryo-electron microscopy [25] (PDB ID: 5HI9), we constructed a structural model of mTRPV2 (Fig. 3d, e). Interestingly, the epitope was located in an $~ 30$-amino-acid loop connecting S5 to the pore helix, known as the pore turret, which is implicated in channel gating, large organic cation permeation, and pore dilation [26]. The core epitope sequence GQEEEPVPY does not exist in other TRP family members (Fig. 3c). In fact, these antibodies did not recognize or inhibit the other TRP channels TRPV1, TRPV3, and TRPC1 (data not shown). As expected based on a sequence alignment (Fig. 3f), the antibodies did not recognize hTRPV2 (data not shown); however, in contrast, the antibodies did recognize hmTRPV2 that was expressed in the HEK293 cells (Fig. S3A). Specifically, mAb88-2 and pAb591 detected hmTRPV2 that was expressed at the plasma membrane (Fig. S3B), and furthermore, inhibited the 2-APB-induced intracellular $\mathrm{Ca}^{2+}$ increase (Fig. S3C). Similar doses of these antibodies had a similar effect on hmTRPV2 as mTRPV2 (Figs. 2 and S2A). Thus, we used the results of the already conducted in vivo mouse experiments (Fig. S2A, B) to estimate an effective antibody dose for use in hamsters.

\section{Protective effects of neutralizing antibodies on J2N-k hamsters with muscular dystrophy}

As the antibodies were effective for hmTRPV2 as well as mTRPV2, we further evaluated whether they are able to alleviate MD in J2N-k hamster models. As reported previously [17], perfusion with high $\mathrm{Ca}^{2+}(5 \mathrm{mM})$ and 

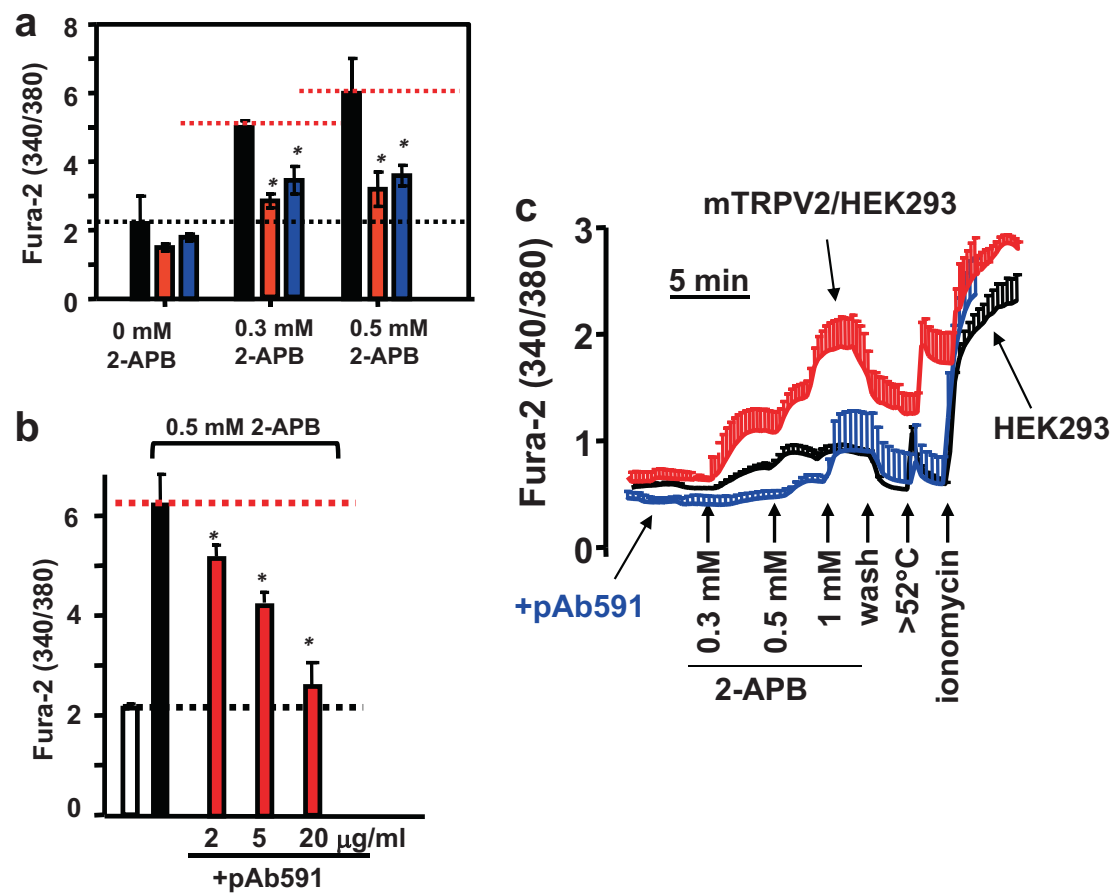

Fig. 2 Produced antibodies inhibits TRPV2-dependent $\mathrm{Ca}^{2+}$ response from the outside. a, b Effect of antibodies on 2-APBinduced intracellular $\mathrm{Ca}^{2+}$ increase measured on 96 -well plates using plate reader. a HEK293 cells expressing mTRPV2 were stimulated with 0.3 or $0.5 \mathrm{mM}$ of 2 -APB in the medium containing $5 \mathrm{mM} \mathrm{CaCl}_{2}$ at acidic condition ( $\mathrm{pH} 6.5$ ) in the absence (black bar) or presence of $0.01 \mathrm{mg} / \mathrm{mL}$ antibodies pAb591 (red) or mAb88-2 (blue). Means \pm S.D $(n=3), * p<0.05$. b Concentration dependence $(2,5$, and $20 \mu \mathrm{g} / \mathrm{mL})$ of antibody pAb591 for inhibition of the 2-APB-induced $\mathrm{Ca}^{2+}$ increase in mouse TRPV2 expressed HEK293 cells. Incubation of antibody was

subsequent 2-APB stimulation markedly raised $\left[\mathrm{Ca}^{2+}\right]_{\mathrm{i}}$ in myotubes prepared from $\mathrm{J} 2 \mathrm{~N}-\mathrm{k}$ hamster skeletal muscles (Fig. 4a), while the same treatment did not induce marked increases in $\left[\mathrm{Ca}^{2+}\right]_{\mathrm{i}}$ in normal controls (J2N-n) [17]. Treatment with the pAb591 antibody suppressed the $\mathrm{Ca}^{2+}$ / 2-APB-induced increase in $\left[\mathrm{Ca}^{2+}\right]_{\mathrm{i}}$ in $\mathrm{J} 2 \mathrm{~N}-\mathrm{k}$ myotubes (Fig. 4a). The monoclonal antibody mAb88-2 also inhibited the $\mathrm{Ca}^{2+}$ increase in $\mathrm{J} 2 \mathrm{~N}-\mathrm{k}$ myotubes (data not shown). These results suggest that $\mathrm{Ca}^{2+}$ influx through TRPV2 contributes substantially to abnormal $\mathrm{Ca}^{2+}$ handling observed in $\mathrm{J} 2 \mathrm{~N}-\mathrm{k}$ myotubes. To examine the effect of the antibody on mechanical stretch-induced muscle degeneration, we applied cyclic stretching for $1 \mathrm{~h}$ to J2N-k myotubes up to $20 \%$ elongation. Myotubes were treated with various doses of pAb591 for $30 \mathrm{~min}$ and subjected to cyclic stretching. Treatment with the antibody reduced stretchinduced CK release, an indicator of muscle damage, from J2N-k myotubes by up to $70 \%$ (Fig. 4b).

To evaluate the effects on MD in vivo, control $\mathrm{IgG}$ or mAb88-2 was intraperitoneally injected into J2N-k hamsters at 9 weeks of age. Two weeks after injection, serum CK levels, indicating muscle injury, were significantly done $90 \mathrm{~min}$ before the measurement. Open bar, no 2-APB and no antibody. Means \pm S.D $(n=3), * p<0.05$. c Changes in intracellular $\mathrm{Ca}^{2+}$ response measured by $\mathrm{Ca}^{2+}$-ratio imaging apparatus. $\mathrm{Ca}^{2+}$ increase in response to extracellular 2-APB $(0.3,0.5$, and $1 \mathrm{mM})$ or high temperature $\left(>52^{\circ} \mathrm{C}\right)$ in untransfected HEK293 cells (black trace) and HEK293 cells expressing mTRPV2 (red trace) loaded with fura- 2 . In one experiment, $10 \mu \mathrm{g} / \mathrm{ml}$ of pAb591 was included $30 \mathrm{~min}$ before the measurement in the medium for HEK293 cells expressing TRPV2 (blue trace). The data represent mean $\pm \mathrm{SD}$ ( $n=$ over 10 cells/group).

reduced in mAb88-2-injected hamsters (Fig. 4c), suggesting that the inhibition of TRPV2 activity prevented muscle damage in J2N-k dystrophic hamsters. We previously reported that TRPV2 is translocated from the intracellular region to the plasma membrane under muscle damage $[14,16]$. As shown in Fig. 4d, endogenous TRPV2 was detected in the plasma membrane of J2N-k hamster skeletal muscles under control conditions (upper left and middle panels of Fig. 4d). Control IgG was detected in the extracellular regions (right upper panel of Fig. 4d), suggesting that injected antibodies can reach the surface of skeletal muscles. In contrast, mAb88-2 was diffusely distributed in muscle cells (right lower panel of Fig. 4d) and endogenous TRPV2 detected by the antibody against the cytosolic domain was also localized mainly in the intracellular region (left and middle lower panel of Fig. 4d). Such antibodyinduced internalization of TRPV2 was also observed in HEK293 cells expressing TRPV2 (Fig. S4). These data suggest that the inhibition of TRPV2 activity by mAb88-2 promotes the internalization of TRPV2. The administration of mAb88-2 markedly reduced the fibrotic area in skeletal muscles of J2N-k dystrophic hamsters (Fig. 4e). 
a

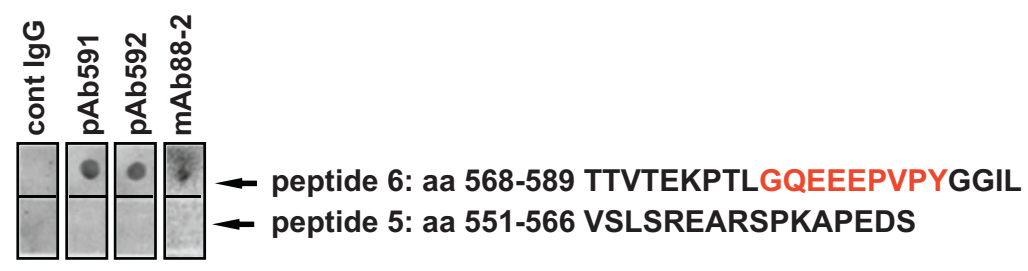

b

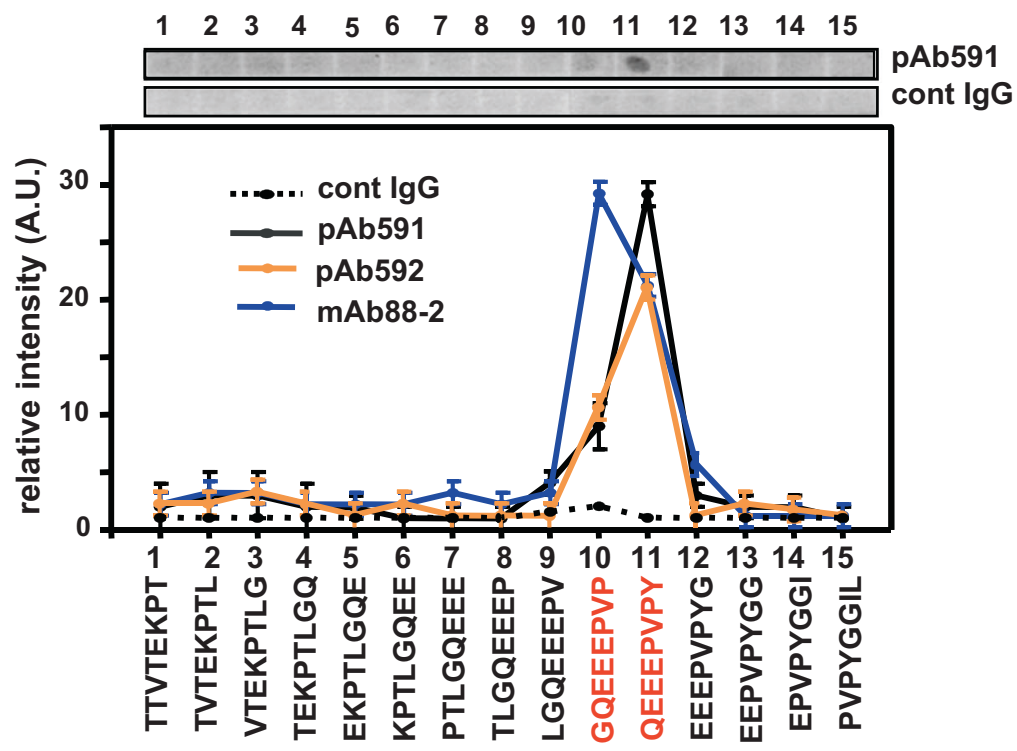

C mTRPV1: VTLIEDGKNNSLPVES----PPHKCRGSACRPGNSYNSLYSTCLELFKFTIGMGDL mTRPV2: VSLSREARSPKAPEDSNTTVTEKPTLGQEEEP-VPYGGILDASLELFKFTIGMGEL mTRPV3: ASLIEKCSK-----------------DKKDCSSYGSFSDAVLELFKLTIGLGDL mTRPV4: VTLLNPCTNMKVCDED-----QSNCTVPTYPACRDSETFSAFLLDLFKLTIGMGDL mTRPV5: YIIFQTEDP------------------DNLGEFSDYPTAMFSTFELFLTIIDG mTRPV6: YIIFQTEDP---------------DELGHFYDYPMALFSTFELFLTIIDG

d
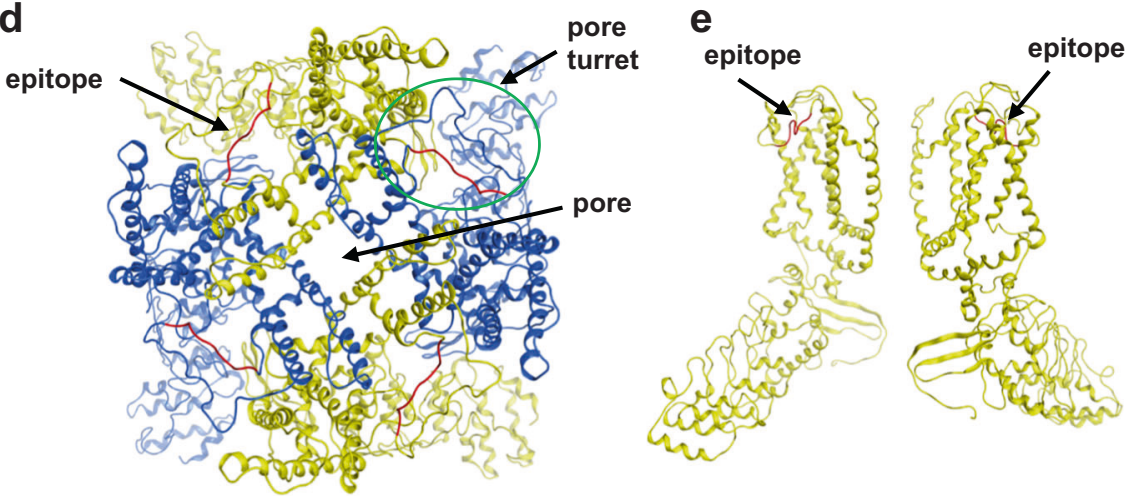

f m

Selective ITRPV2: VSLSREARSPKAPEDNNSTVTEQPTVGQEEEP--APYRSILDASLELFKFTIGMGEL hmTRPV2: VSLSREAQSPKAPADNNTAVTEQPMVGQEEEA--APYGGILDASLELFKFTIGMGEL hTRPV2: VSLSQEAWRPEAPTGPNATESVQPMEGQEDEGNGAQYRGILEASLELFKFTIGMGEL 
Fig. 3 Antibody production and epitope mapping. a Nitrocellulose membranes dotted by each peptide (peptide 6, aa 568-589: peptide 5, aa 551-566 corresponding to the third extracellular loop of mouse TRPV2 between S5 and S6, see Fig. S1A) were stained with indicated antibodies. While pAb591 and pAb592 are antiserum from two rabbits immunized with peptide $6, \mathrm{mAb} 88-2$ is monoclonal antibody screened for inhibition of TRPV2-induced $\mathrm{Ca}^{2+}$ response. b Fifteen peptides (8mer for each) within the antigen peptide sequence (aa 568-589) were synthesized and dotted on the membrane, and followed by immunostaining with indicated antibodies. Two representative photographs show the blots stained using pAb591 or control IgG. Signal intensity was plotted for tested antibodies. The sequence marked by red color was identified as a common epitope for three tested antibodies. c Amino acid sequence alignment among the third extracellular loops of mouse TRPV1 to TRPV6. Sequence used as an antigen for functional antibody (pAb591) was indicated yellow. The peptide antigen for the functional TRPV1 antibody reported by Klionsky et al. [35] is shown green. d, e Tetrameric mouse TRPV2 structure model was constructed from rat TRPV2 model (PDB ID: 5HI9) and the epitope location was analyzed by Molecular Operating Environment (Chemical Computing Group, Canada). A parallel view to plasma membrane from the extracellular side (d) and a vertical view to plasma membrane, showing two facing subunits (e). Segments marked by red color between S5 and S6 helices indicate the location of epitope. f Sequence alignment of TRPV2 among different mammalian species. Position of epitope is marked by red color. $\mathrm{m}$ mouse, $\mathrm{r}$ rat, $\mathrm{hm}$ hamster, $\mathrm{h}$ human.

\section{Protection of heart failure by neutralizing antibodies in J2N-k hamsters with cardiomyopathy}

We next studied the effects of the antibodies on heart malfunctions using $\delta$-sarcoglycan-deficient J2N-k hamsters, which develop DCM as well as MD. First, we checked the localization of TRPV2 in freshly isolated cardiomyocytes. Staining with mAb88-2 followed by an Alexa488conjugated secondary antibody was used to detect hmTRPV2 from outside of cardiomyocytes from J2N-k hamsters, in plasma membranes co-stained with rhodaminelabeled wheat germ agglutinin (Fig. 5a). Intense sarcolemmal staining with mAb88-2 was observed only in cardiomyocytes from J2N-k hamsters (Fig. 5a), consistent with our previous observations [15] that TRPV2 is translocated from the intracellular compartments to the plasma membrane in cardiomyopathy. The treatment of cardiomyocytes with tranilast, a TRPV2 blocker, reduced the sarcolemmal localization of TRPV2 (Fig. 5a), suggesting that TRPV2 activity is required for the plasma membrane retention of TRPV2 itself. Figure $5 b$ and $c$ show $\mathrm{Ca}^{2+}$ transients under electrical stimulation at $1 \mathrm{~Hz}$. Diastolic $\mathrm{Ca}^{2+}$ levels were significantly higher (J2N-k, $0.63 \pm 0.03$ vs. J2N-n, $0.52 \pm 0.03$ ) and the increase in $\mathrm{Ca}^{2+}$ by stimulation was lower in $\mathrm{J} 2 \mathrm{~N}-\mathrm{k}$ cardiomyocytes. An abnormal $\left[\mathrm{Ca}^{2+}\right]_{\mathrm{i}}$ increase was observed in response to exposure to 2-APB, whereas the $\mathrm{Ca}^{2+}$ transient was not so affected by 2-APB in control J2N-n cardiomyocytes. The abnormal $\left[\mathrm{Ca}^{2+}\right]_{\mathrm{i}}$ increase induced by 2-APB and higher diastolic $\mathrm{Ca}^{2+}$ levels observed in J2N-k cardiomyocytes were inhibited by mAb88-2 (Fig. 5c) as well as tranilast (Fig. 5b).
Cardiomyopathic (J2N-k) hamsters at 9 weeks of age, (i.e., after initiation of the expected heart abnormalities), were intraperitoneally injected twice (once a week) with $\mathrm{mAb} 88-2$ at a dose of $0.5 \mathrm{mg} / \mathrm{kg}$ for 2 weeks until reaching 11 weeks old. The serum concentration of mAb88-2 after a single injection was generally stable for 1 week, although the decay speed varied among animals (Fig. S2B). MAb882 resulted in a significant improvement in cardiac function as measured by echocardiography; in particular, enddiastolic and end-systolic left ventricular internal dimensions (LVIDd and LVIDs, respectively) were shortened substantially by injection with mAb88-2 (Fig. 6a). FS and ejection fractions (EF) were improved to nearly normal levels (Fig. $6 \mathrm{~b}$ and Table S1), while treatment with control IgG was not effective (Fig. $6 \mathrm{~b}$ and Table S1). While TRPV2 was detected in the sarcolemma of J2N-k hamster hearts injected with control IgG, TRPV2 levels were very low in the plasma membrane after injection with mAb88-2 (Fig. 6c). Thus, treatment with mAb88-2 markedly reduced the surface accumulation of TRPV2 and thereby prevented heart failure.

\section{Protection of heart failure by neutralizing antibodies in a 4C30 mouse model with dilated cardiomyopathy at the end-stage}

We studied the effect of mAb88-2 on end-stage DCM using 4C30 mice, a recently developed mouse model for human DCM. The 4C30 mice died within 30-40 weeks of age due to deteriorating heart failure [15]. 4C30 mice showed cardiac dysfunction with a low FS $(<20 \%)$ at 25 weeks of age and more severe dysfunction at 27 weeks $(\mathrm{FS}<10 \%)$ (Table S2). However, mAb88-2 treatment dramatically prevented the DCM histochemical morphology as well as echocardiographic parameters of hearts (Fig. 7a and Table S2). At 27 weeks, both the interventricular septal walls (IVSW) and left ventricular free walls (LVFW) of mice with DCM (IVSW, $0.49 \pm 0.09 \mathrm{mM}$; LVFW, $0.59 \pm$ $0.10 \mathrm{mM}$ ) were significantly thinner than those of WT mice (IVSW, $1.01 \pm 0.13 \mathrm{mM}$; LVFW, $1.08 \pm 0.13 \mathrm{mM}$ ); however, IVSW thinning was improved by treatment with $0.25 \mathrm{mg}$ (DCM, $0.92 \pm 0.08 \mathrm{mM}$ ) or $0.5 \mathrm{mg}$ (WT, $1.10 \pm$ $0.17 \mathrm{mM}$; DCM, $0.98 \pm 0.03 \mathrm{mM}) \mathrm{mAb} 88-2$. Likewise, treatment with $0.25 \mathrm{mg}$ (DCM, $1.02 \pm 0.24 \mathrm{mM}$ ) or $0.5 \mathrm{mg}$ (WT, $1.20 \pm 0.09 \mathrm{mM}$; DCM, $1.12 \pm 0.24 \mathrm{mM}$ ) improved LVFW thinning, ( $n=3$ separate hearts/group). Treatment with mAb88-2 reduced the heart weight to a nearly normal level (Fig. 7b) and significantly improved heart function in a dose-dependent manner (Fig. 7e and Table S2) but did not affect other hemodynamic parameters (Fig. 7c, d). Outstanding fibrosis was observed throughout the heart, but especially at the apex and interseptum (Fig. 7f), and this was highly reduced by mAb88-2 treatment (Fig. 7a, f, g). 

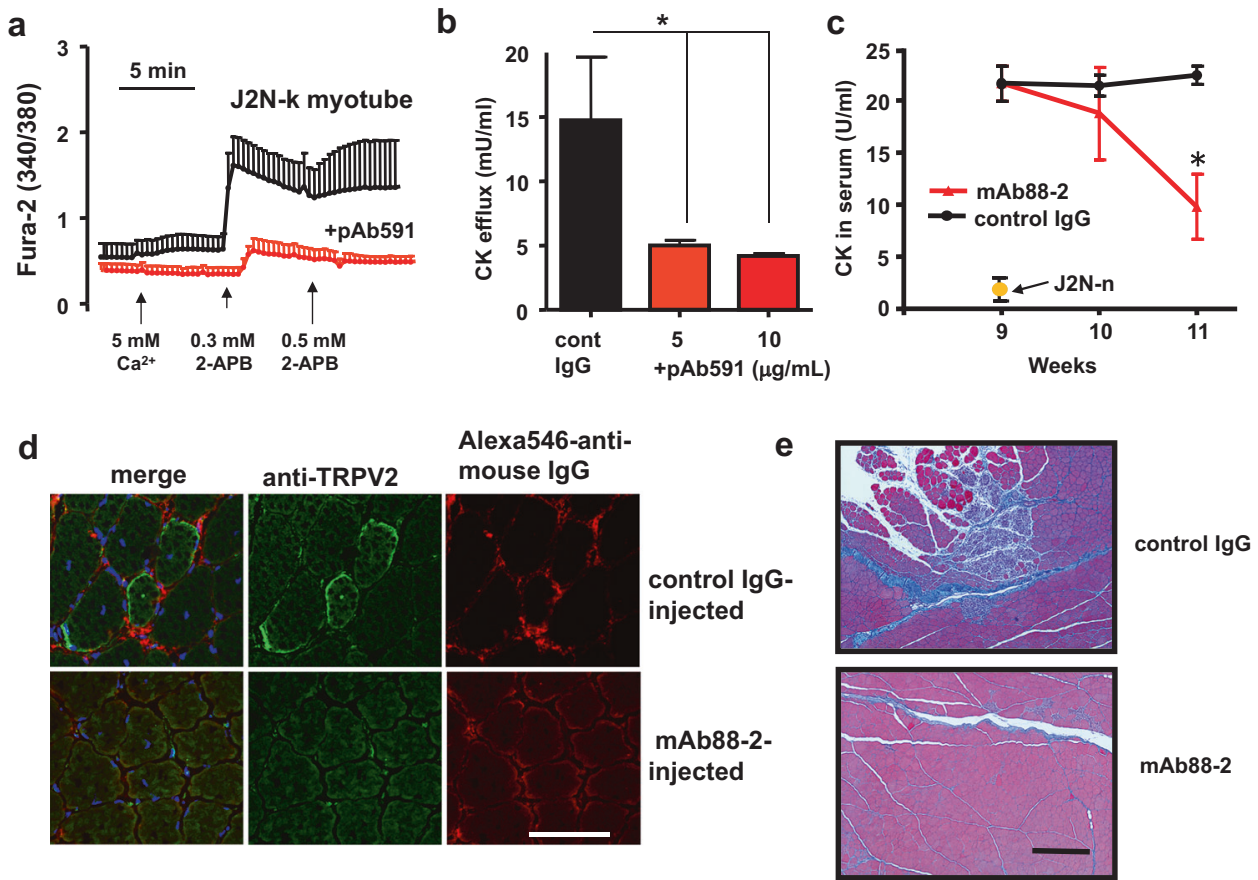

Fig. 4 Prevention of skeletal muscle damage by TRPV2neutralizing antibodies in dystrophic hamsters. a Typical traces from the ratiometric scanning of fura- 2 fluorescence in myotubes prepared from dystrophic (J2N-k) hamsters. Fura-2-loaded myotubes were placed in BSS containing $0.5 \mathrm{mM} \mathrm{CaCl}_{2}$, then exposed to BSS containing $5 \mathrm{mM} \mathrm{CaCl}_{2}$ at $\mathrm{pH} 6.5$, and then 2 -APB $(0.3$ and $0.5 \mathrm{mM})$ in the absence (black line) or presence of antibody pAb591 $(10 \mu \mathrm{g} / \mathrm{mL})$ (red). b Effect of antibody on the stretch-induced CK release from the myotubes. Myotubes were placed on the elastic silicon chambers and exposed to the continuous stretching in the absence or presence of pAb591 (5 or $10 \mu \mathrm{g} / \mathrm{ml})$ as described under "Materials and methods." The levels of CK released into the medium were measured. Means \pm SD $(n=3), * p<0.05$. c Antibody mAb88-2 or control $\mathrm{IgG}$ were

Half of the 4C 30 mice (five of ten) died before 27 weeks, but all mAb88-2-treated 4C30 mice (nine of nine) were alive at 27 weeks. In wild-type mice, mAb88-2 did not have detrimental effects on cardiovascular parameters (Fig. 7a-g) or other parameters in a safety test, even for an overdose (see "Materials and methods"). Thus, the functional antibody against TRPV2 also effectively ameliorated severe DCM even in the end-stage and is promising for future therapy.

\section{Discussion}

We successfully produced monoclonal and polyclonal antibodies that inhibit the function of TRPV2 in vitro with high specificity and potency. The antibodies recognize TRPV2 in the plasma membrane from the outside of cells and inhibit cytosolic $\mathrm{Ca}^{2+}$ increases via TRPV2. Remarkably, the antibodies exhibited significant beneficial effects in cardiomyopathy and MD in mouse and hamster models. injected into J2N-k hamsters at 9 weeks of age, and CK level in serum was measured at indicated times. Means $\pm \operatorname{SD}(n=3), * p<0.05$ versus control IgG injection in J2N-k hamsters. d Immunofluorescence of the frozen section of skeletal muscles with DAPI (blue in merged image) and rabbit anti-TRPV2 antibody against C-terminal cytoplasmic domain (anti-TRPV2) to detect the endogenous TRPV2 (green). The same section was triple stained with the Alexa546-conjugated secondary anti-mouse $\operatorname{IgG}$ (red) to detect the tissue localization of each antibody (control IgG or mAb88-2) injected. Scale bars: $100 \mu \mathrm{M}$. e Masson's trichrome staining of skeletal muscle sections from $\mathrm{J} 2 \mathrm{~N}-\mathrm{k}$ hamsters intraperitoneally injected with control $\mathrm{IgG}$ or mAb88-2. Scale bars: $100 \mu \mathrm{M}$.

Thus, the antibodies developed in this study have promising clinical applications and may be used as specific inhibitors against TRPV2.

It is generally difficult to obtain functional antibodies against multispanning membrane proteins, such as TRPV2 [27-30]. The production of neutralizing antibodies against TRPV2 has been limited by the relatively small extracellular loops for epitope candidates and high conservation at the primary amino acid level, making it difficult to obtain a robust immune response in mammalian hosts [31]. To raise monoclonal antibodies that bind to extracellular regions of multispanning membrane proteins, full-length proteins in a membrane context by using whole cells or liposome-reconstituted proteins have been used [32]. Therefore, after preliminary analyses using various hosts, we used mice with an immune disease as host animals and HEK293 cells expressing mTRPV2 as an immunogen to generate functional monoclonal antibodies. Interestingly, the epitope for mAb88-2 was located in the third extracellular loop (E3) of TRPV2, the same region as epitopes 
a
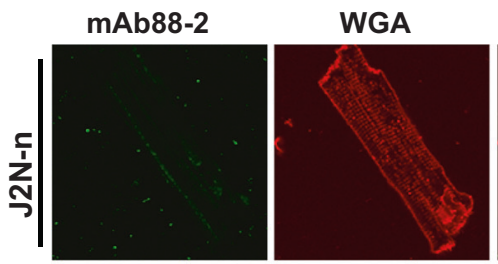

Merge
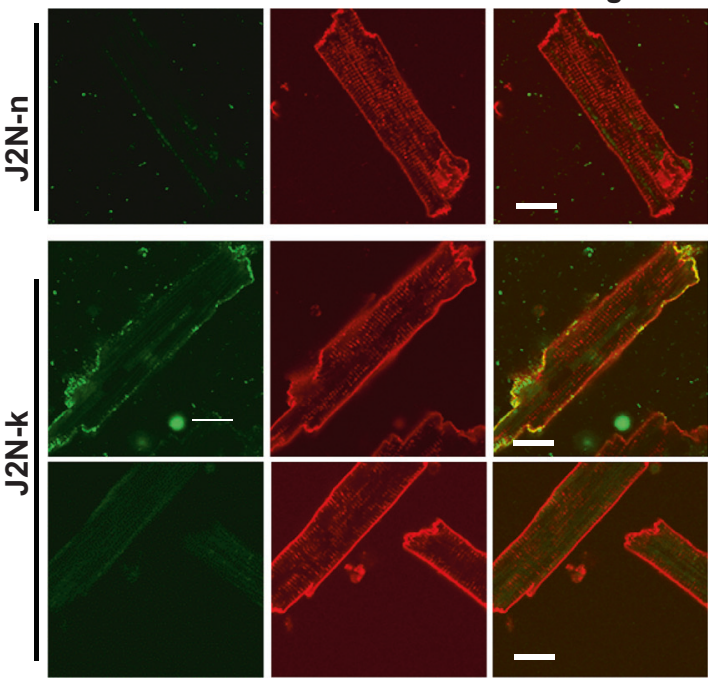

b
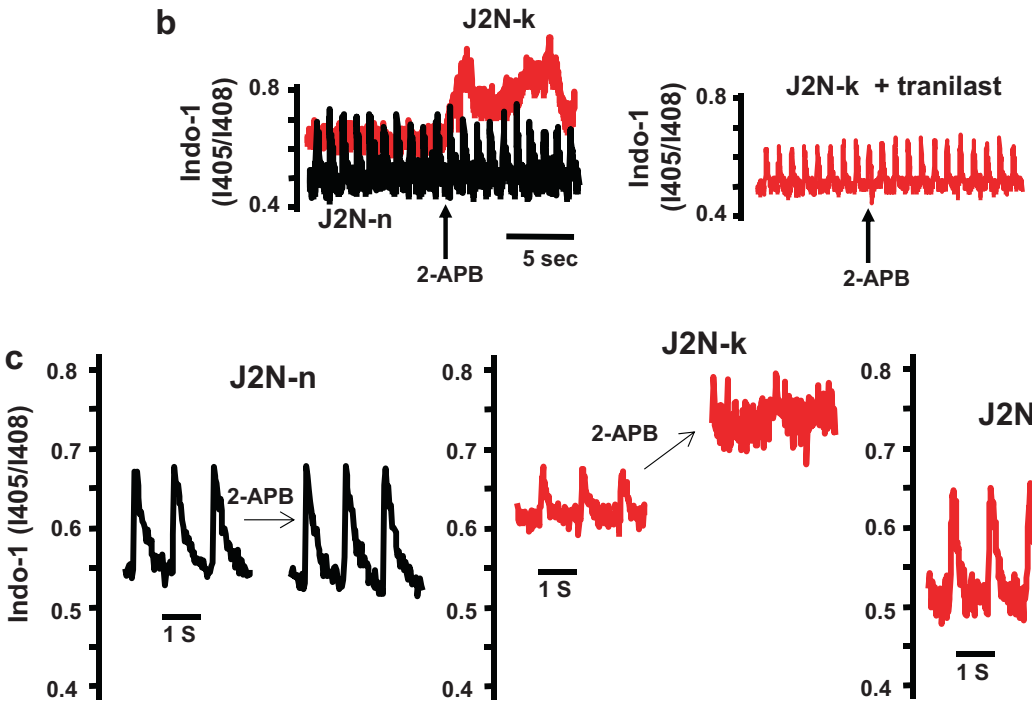

J2N-k

Fig. 5 TRPV2 localization and the effect of $\mathrm{mAb88}-2$ on $\mathrm{Ca}^{2+}$ response in isolated cardiomyocytes from hamsters. a Cardiomyocytes isolated from $\mathrm{J} 2 \mathrm{~N}-\mathrm{n}$ or $\mathrm{J} 2 \mathrm{~N}-\mathrm{k}$ hamsters were stained with mAb88-2 followed by Alexa488-conjugated secondary antibody and rhodamine conjugated-WGA (scale bar, $20 \mu \mathrm{M}$ ). In one experiment, cardiomyocytes from $\mathrm{J} 2 \mathrm{~N}-\mathrm{k}$ hamsters were treated for $30 \mathrm{~min}$ with $300 \mu \mathrm{M}$ tranilast before staining. Their staining was done for $30 \mathrm{~min}$ at $4{ }^{\circ} \mathrm{C}$ and washed with Tyrode solution. The images were captured under the same conditions where the values of both excitation lasers and $\mathrm{HV}$ were fixed. b Intracellular $\mathrm{Ca}^{2+}$ transient and acute effects of 2-APB. Representative traces of the Indo-1 ratio in single

against polyclonal antibodies in rabbits, indicating that the E3 region shows high immunogenicity and is important for channel activity.

We obtained the first functional antibodies against TRPV2 with an epitope in the E3 region. The epitope identified in our study was located in the pore turret (Fig. 3d, e), which contributes to expansion of the upper gate, and is poorly resolved or deleted for structure

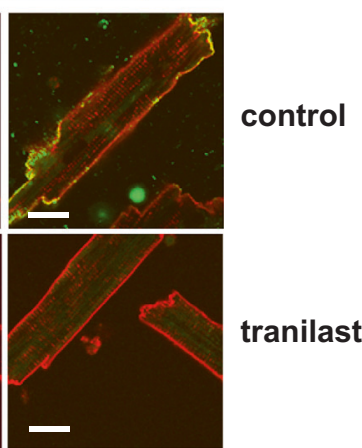


a

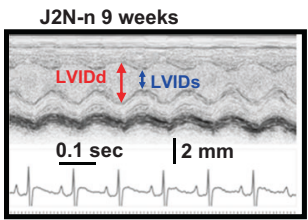

J2N-k 9 weeks

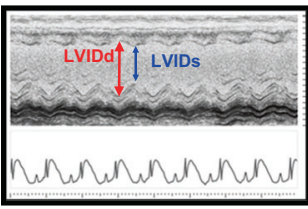

b

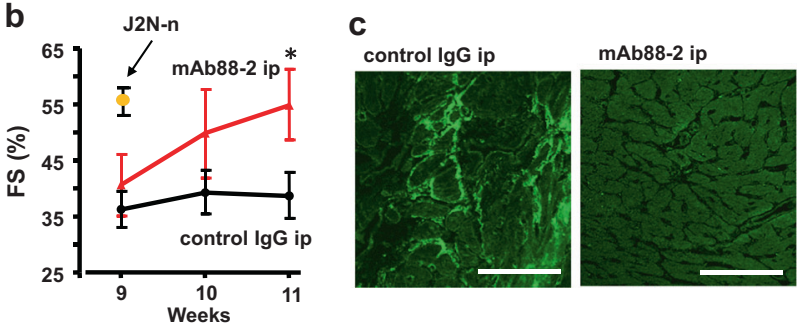

Fig. 6 Protection against cardiac dysfunction by mAb88-2 administration in $\mathbf{J} 2 \mathbf{N}-\mathbf{k}$ hamsters. a Representative echocardiographs (M-mode) obtained from J2N-k and J2N-n (normal counterparts) hamsters at 9 or 11 weeks of age. Control IgG or mAb88-2 antibodies were intraperitoneally injected into J2N-k hamsters as described under "Materials and methods." LVIDd and LVIDs indicate the left ventricular internal dimension at diastole and systole, respectively. b Time-dependent effect of mAb88-2 intraperitoneal (ip) injection on the fractional shortening (FS) in J2N-k hamsters. Data represent means $\pm \mathrm{SD}(n=3), * p<0.05$ versus control $\mathrm{IgG}$ in $\mathrm{J} 2 \mathrm{~N}-\mathrm{k}$. c Immunofluorescence of the frozen section of cardiac muscles with rabbit anti-TRPV2 antibody against C-terminal cytoplasmic region to detect the endogenous TRPV2, in J2N-k hamsters at 11 weeks of age, Scale bars: $100 \mu \mathrm{M}$.

determinants for 2-APB binding [34], and thus the turret may not be critical for 2-APB binding. Furthermore, we observed that in addition to the response to 2-APB, our antibodies effectively reduced high temperature- or high $\mathrm{Ca}^{2+}$-induced cytosolic $\mathrm{Ca}^{2+}$ increases. These findings suggest that the antibodies change the conformation of the upper gate of TRPV2 to make it narrower or to stabilize the closed conformation, rather than inhibit the interaction of TRPV2 with 2-APB. In addition to measuring TRPV2mediated $\mathrm{Ca}^{2+}$ influx to estimate TRPV2 activity, we also examined the effects of the antibodies on TRPV2 channel activity under voltage-clamp conditions. We showed that the antibodies reduced the observed 2-APB-induced current

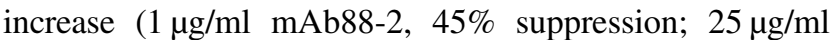
pAb591, 73\% suppression).

Recently, some functional antibodies targeting TRPV1 and TRPV2 have been reported to use [35, 36], however, epitopes for these antibodies are different from the epitope within the E3 region identified in our study. Interestingly, mAb88-2 promoted the cellular internalization of TRPV2 in
HEK293 cells (Fig. S4), suggesting that antibody-mediated inhibition of TRPV2 activity also occurs by a reduced channel density in the plasma membranes, in addition to the possible inhibition of ion permeation. We previously showed that TRPV2 accumulates in the sarcolemma of the heart and skeletal muscles in animals and patients with DCM or MD, respectively $[14,15]$. In this study, we also confirmed that TRPV2 is expressed in the sarcolemma of cardiomyocytes prepared from $\mathrm{J} 2 \mathrm{~N}-\mathrm{k}$, but not $\mathrm{J} 2 \mathrm{~N}-\mathrm{n}$ hamsters using mAb88-2 recognizing the extracellular loop of TRPV2 (Fig. 5a). A broad TRPV2 inhibitor, tranilast, caused TRPV2 to disappear from the plasma membrane of cardiomyocytes (Fig. 5a), consistent with our previous results [15] showing that the retention of TRPV2 in the sarcolemma requires the activity of TRPV2. Antibodymediated internalization has been reported in various ion channels and transporters expressed on the cell surface, such as the store-operated $\mathrm{Ca}^{2+}$ channel subunit Orail [37], two pore domain $\mathrm{K}^{+}$channels [38], the $\mathrm{ABC}$ transporter family member $\mathrm{ABCG} 2$ [39], and purinergic receptor $\mathrm{P} 2 \mathrm{X} 3$ [40]. In some of these studies, antibody interactions were suggested to lock the proteins in a discrete conformation within the reaction cycle, leading to endocytosis. It is likely that mAb88-2 stabilizes the TRPV2 channel conformation to the closed state, thereby promoting efficient cellular internalization via the intracellular trafficking pathway. Further research is needed to elucidate the mechanisms by which mAb88-2 exerts these effects.

Antibody-mediated internalization has strong therapeutic potential, since the surface density of TRPV 2 can be easily decreased from the extracellular side, as confirmed by our in vivo analyses. Intraperitoneally administering mAb88-2 reduced endogenous TRPV2 activity in the sarcolemma of skeletal and cardiac muscles in J2N-k hamsters. It also prevented muscle damage in $\mathrm{MD}$, as shown by reduced serum CK levels and muscle fibrosis. A beneficial effect was also observed in the DCM hearts of J2N-k hamsters. The administration of mAb88-2 dramatically improved cardiac function; FS and EF recovered to the levels in normal hamsters (J2N-n) (Fig. 6a, b and Table S1). High diastolic $\mathrm{Ca}^{2+}$ levels and small peak amplitudes of $\mathrm{Ca}^{2+}$ transients were observed in DCM cardiomyocytes, which would lead to increases in LVIDd at diastole and LVIDs at systole in vivo. These abnormalities were dramatically improved by mAb88-2. Further, mAb88-2 also had beneficial effects in 4C30 mice with end-stage DCM; it prevented cardiac dilation, reduced heart weight and fibrosis, and improved cardiac function, with no obvious detrimental effects on healthy control mice, even for an overdose (over $4 \times$ the effective dose). Thus, the functional antibody against TRPV2, probably via the cellular internalization of the channel, effectively ameliorates DCM with different underlying causes. Consistent with our results, the genetic 
Fig. 7 Protection against dilated cardiomyopathy by mAb88-2 administration in the mouse model $4 \mathrm{C} 30$.

a Representable Masson's trichrome staining of cardiac sections from wild-type and cardiomyopathic 4C30 mice at 27 weeks of age. The monoclonal antibody mAb88-2 $(0.25$ or $0.5 \mathrm{mg} / \mathrm{kg}$ ) were intraperitoneally injected into 4C30 mice once a week from 25 weeks of age. Amounts of injected antibodies were adjusted to $0.5 \mathrm{mg} / \mathrm{kg}$ by control IgG. Scale bar: $1 \mathrm{mM}$. b Effects of mAb88-2 injection on heart weight/body weight ratio (HW/ $\mathrm{BW}),(\mathbf{c})$ heart rate, (d) mean blood pressure (MBP) and (e) fractional shortening (FS). f Representative magnified images of the Masson's trichrome staining of cardiac sections, including apical heart septum. Scale bar, $150 \mu \mathrm{M}$. g Summarized data of fibrosis areas. b-e, $\mathbf{g}$ Data are shown as the mean \pm SD $(n=4-5)$. * $p<$ 0.05 vs. control (i.e., 27 weeks 4C30 mice not provided with mAb88-2 treatment). a
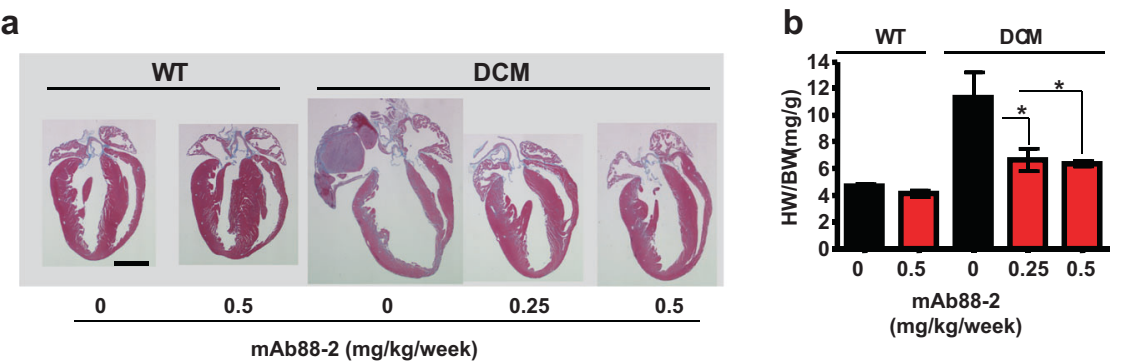

C
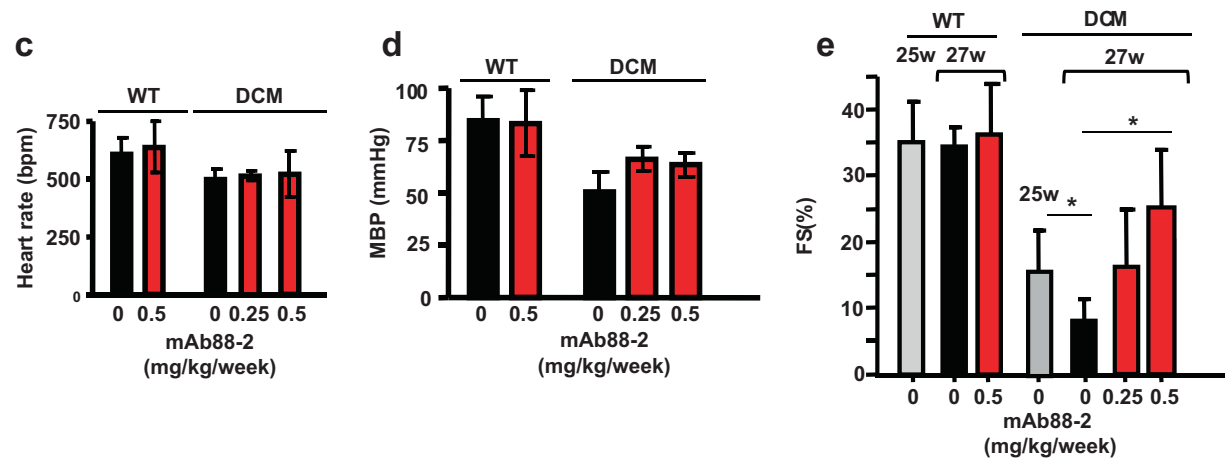

f
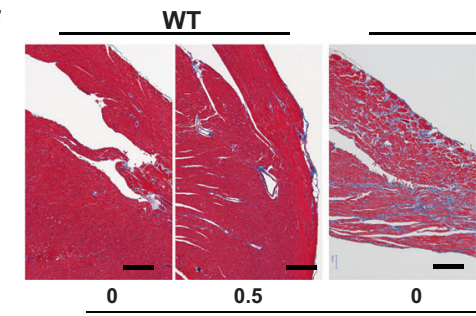

DCM

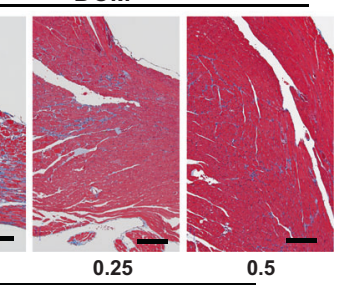

mAb88-2 (mg/kg/week)

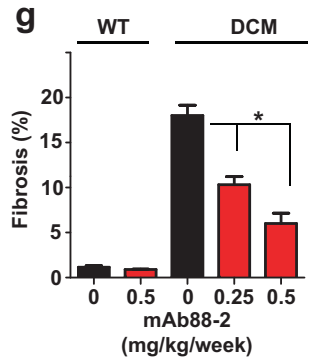

ablation of TRPV2 reduces hypertrophy caused by transverse aortic constriction [41] and improves cardiac performance following myocardial infarction [42, 43]. Further, while aging is known to reduce cardiac performance and to result in fibrosis and hypertrophy in mice, these agingrelated symptoms are retarded in TRPV2-knockout mice [44]. These studies together with ours suggest that TRPV2 plays an important role in the development of age- as well as mechanical stress-induced cardiac remodeling.

Antibody-based therapy is a rapidly growing field. Therapeutic antibodies have been used to treat cancer and immune diseases by targeting receptors or secreted proteins $[45,46]$. Although many ion channels are established as drug targets, limited antibody therapeutics against ion channels have been developed, especially for heart failure therapy. To our knowledge, this is the first demonstration that anti-TRP channel antibodies are effective for the treatment of heart failure or degenerative muscle diseases, at least in animal models. We recently reported that the TRPV2 inhibitor tranilast and new chemicals identified based on the structure of tranilast prevent the severity of cardiac dysfunction in animal models and in cardiomyopathic patients with MD [15, 17, 47]. However, tranilast has various effects, such as inhibitory effects on urate transporters [19], Nod-like receptor pyrin domain containing three inflammasome [18], and sepiaterin reductase [48]. Moreover, the half-life of tranilast in humans is $\sim 5 \mathrm{~h}$, its continuous intake would be essential for maintaining the inhibitory effect. Although tranilast has few or mild side effects, continuous administration for more than 30 days may increase the chance of adverse effects, such as liver damage, anemia, and renal dysfunction. The risk or severity of adverse effects can be increased when tranilast is taken with the anticoagulant drug warfarin (https://www.drugbank.ca/drugs/DB07615). Compared with tranilast, mAbs have many potential benefits beyond selectivity, including accessibility, a longer duration of action leading to reduced dosing, mitigation of offtarget effects, and improved safety.

In summary, we developed functional antibodies against TRPV2 with remarkable protective effects against DCM as well as MD. The antibodies are rodent TRPV2-specific. The development of antibodies specific to hTRPV2 is required for clinical purposes. Our results provide a basis for future advances in the treatment of severe heart failure as well as DCM. 
Acknowledgements We would like to thank Mrs Hitomi Ohtake and Madoka Hirayama for technical assistance. We would also like to thank Dr Ryu Nagata (Osaka University) for helpful discussions and Dr Kiichiro Tomoda (Osaka Medical Collage) for technical assistance with the structural modeling of mTRPV2. This work was funded by the Japan Society for the Promotion of Science Grant-in-Aid for Scientific Research (C) [grant number 17K09598 to YI] and Grant-in-Aid for Research on Nervous and Mental Disorders of NCNP [grant number 28-6 to $\mathrm{YI}]$.

\section{Compliance with ethical standards}

Conflicts of interest The authors declare that they have no conflict of interest.

Publisher's note Springer Nature remains neutral with regard to jurisdictional claims in published maps and institutional affiliations.

\section{References}

1. Hughes SE, McKenna WJ. New insights into the pathology of inherited cardiomyopathy. Heart. 2005;91:257-64.

2. Fatkin D, Graham RM. Molecular mechanisms of inherited cardiomyopathies. Physiol Rev. 2002;82:945-80.

3. Seidman JG, Seidman C. The genetic basis for cardiomyopathy: from mutation identification to mechanistic paradigms. Cell. 2001;104:557-67.

4. Jefferies JL, Towbin JA. Dilated cardiomyopathy. Lancet. 2010;375:752-62.

5. Yancy CW, Jessup M, Bozkurt B, Butler J, Casey DE Jr., Drazner $\mathrm{MH}$, et al. $2013 \mathrm{ACCF} / \mathrm{AHA}$ guideline for the management of heart failure: a report of the American College of Cardiology Foundation/American Heart Association Task Force on Practice Guidelines. J Am Coll Cardiol. 2013;62:e147-239.

6. Ponikowski P, Voors AA, Anker SD, Bueno H, Cleland JG, Coats AJ, et al. 2016 ESC Guidelines for the diagnosis and treatment of acute and chronic heart failure: The Task Force for the diagnosis and treatment of acute and chronic heart failure of the European Society of Cardiology (ESC). Developed with the special contribution of the Heart Failure Association (HFA) of the ESC. Eur J Heart Fail. 2016;18:891-975.

7. Zannad F, Gattis Stough W, Rossignol P, Bauersachs J, McMurray JJ, Swedberg K, et al. Mineralocorticoid receptor antagonists for heart failure with reduced ejection fraction: integrating evidence into clinical practice. Eur Heart J. 2012; 33:2782-95.

8. Campbell KP, Kahl SD. Association of dystrophin and an integral membrane glycoprotein. Nature. 1989;338:259-62.

9. Campbell KP. Three muscular dystrophies: loss of cytoskeletonextracellular matrix linkage. Cell. 1995;80:675-9.

10. McNally EM, Mestroni L. Dilated cardiomyopathy: genetic determinants and mechanisms. Circ Res. 2017;121:731-48.

11. Nigro V, Okazaki Y, Belsito A, Piluso G, Matsuda Y, Politano L, et al. Identification of the Syrian hamster cardiomyopathy gene. Hum Mol Genet. 1997;6:601-7.

12. Nakamura TY, Iwata Y, Sampaolesi M, Hanada H, Saito N, Artman M, et al. Stretch-activated cation channels in skeletal muscle myotubes from sarcoglycan-deficient hamsters. Am J Physiol Cell Physiol. 2001;281:C690-9.

13. Sampaolesi M, Yoshida T, Iwata Y, Hanada H, Shigekawa M. Stretch-induced cell damage in sarcoglycan-deficient myotubes. Pflugers Arch. 2001;442:161-70.

14. Iwata Y, Katanosaka Y, Arai Y, Komamura K, Miyatake K, Shigekawa M. A novel mechanism of myocyte degeneration involving the $\mathrm{Ca}^{2+}$-permeable growth factor-regulated channel. J Cell Biol. 2003;161:957-67.

15. Iwata Y, Ohtake H, Suzuki O, Matsuda J, Komamura K, Wakabayashi S. Blockade of sarcolemmal TRPV2 accumulation inhibits progression of dilated cardiomyopathy. Cardiovasc Res. 2013;99:760-8.

16. Iwata Y, Katanosaka Y, Arai Y, Shigekawa M, Wakabayashi S. Dominant-negative inhibition of $\mathrm{Ca}^{2+}$ influx via TRPV2 ameliorates muscular dystrophy in animal models. Hum Mol Genet. 2009; 18:824-34.

17. Iwata Y, Katayama Y, Okuno Y, Wakabayashi S. Novel inhibitor candidates of TRPV2 prevent damage of dystrophic myocytes and ameliorate against dilated cardiomyopathy in a hamster model. Oncotarget. 2018;9:14042-57.

18. Huang Y, Jiang $\mathrm{H}$, Chen Y, Wang X, Yang Y, Tao J, et al. Tranilast directly targets NLRP3 to treat inflammasome-driven diseases. EMBO Mol Med. 2018;10:e8689.

19. Mandal AK, Mercado A, Foster A, Zandi-Nejad K, Mount DB. Uricosuric targets of tranilast. Pharmacol Res Perspect. 2017;5: e00291.

20. Suzuki O, Kanai T, Nishikawa T, Yamamoto Y, Noguchi A, Takimoto K, et al. Adult onset cardiac dilatation in a transgenic mouse line with Galbeta1,3GalNAc alpha2,3-sialyltransferase II (ST3Gal-II) transgenes: a new model for dilated cardiomyopathy. Proc Jpn Acad Ser B Phys Biol Sci. 2011;87:550-62.

21. Nakamura TY, Iwata Y, Arai Y, Komamura K, Wakabayashi S. Activation of $\mathrm{Na}^{+} / \mathrm{H}^{+}$exchanger 1 is sufficient to generate $\mathrm{Ca}^{2+}$ signals that induce cardiac hypertrophy and heart failure. Circ Res. 2008;103:891-9.

22. Maekawa K, Hirayama A, Iwata Y, Tajima Y, Nishimaki-Mogami $\mathrm{T}$, Sugawara S, et al. Global metabolomic analysis of heart tissue in a hamster model for dilated cardiomyopathy. J Mol Cell Cardiol. 2013;59:76-85.

23. Kuhara M, Yoshino T, Shiokawa M, Okabe T, Mizoguchi S, Yabuhara A, et al. Magnetic separation of human podocalyxinlike protein 1 (hPCLP1)-positive cells from peripheral blood and umbilical cord blood using anti-hPCLP1 monoclonal antibody and protein A expressed on bacterial magnetic particles. Cell Struct Funct. 2009;34:23-30.

24. Iwata Y, Katanosaka Y, Shijun Z, Kobayashi Y, Hanada H, Shigekawa $\mathrm{M}$, et al. Protective effects of $\mathrm{Ca}^{2+}$ handling drugs against abnormal $\mathrm{Ca}^{2+}$ homeostasis and cell damage in myopathic skeletal muscle cells. Biochem Pharmacol. 2005;70:740-51.

25. Huynh KW, Cohen MR, Jiang J, Samanta A, Lodowski DT, Zhou $\mathrm{ZH}$, et al. Structure of the full-length TRPV2 channel by cryo-EM. Nat Commun. 2016;7:11130.

26. Zheng J, Ma L. Structure and function of the thermoTRP channel pore. Curr Top Membr. 2014;74:233-57.

27. Hutchings CJ, Colussi P, Clark TG. Ion channels as therapeutic antibody targets. MAbs. 2019;11:265-96.

28. Wilkinson TC, Gardener MJ, Williams WA. Discovery of functional antibodies targeting ion channels. J Biomol Screen. 2015;20:454-67.

29. Haustrate A, Hantute-Ghesquier A, Prevarskaya N, Lehen'kyi V. Monoclonal antibodies targeting ion channels and their therapeutic potential. Front Pharmacol. 2019;10:606.

30. Wilkinson TC, Gardener MJ, Williams WA. Discovery of functional antibodies targeting ion channels. J Biomol Screen. 2019;20:454-67.

31. Ching KH, Collarini EJ, Abdiche YN, Bedinger D, Pedersen D, Izquierdo $\mathrm{S}$, et al. Chickens with humanized immunoglobulin genes generate antibodies with high affinity and broad epitope coverage to conserved targets. MAbs. 2018;10:71-80.

32. Hutchings CJ, Koglin M, Marshall FH. Therapeutic antibodies directed at $G$ protein-coupled receptors. MAbs. 2010;2: 594-606. 
33. Zubcevic L, Herzik MA Jr., Chung BC, Liu Z, Lander GC, Lee SY. Cryo-electron microscopy structure of the TRPV2 ion channel. Nat Struct Mol Biol. 2016;23:180-6.

34. Juvin V, Penna A, Chemin J, Lin YL, Rassendren FA. Pharmacological characterization and molecular determinants of the activation of transient receptor potential V2 channel orthologs by 2-aminoethoxydiphenyl borate. Mol Pharmacol. 2007; 72:1258-68.

35. Klionsky L, Tamir R, Holzinger B, Bi X, Talvenheimo J, Kim H, et al. A polyclonal antibody to the prepore loop of transient receptor potential vanilloid type 1 blocks channel activation. J Pharmacol Exp Ther. 2006;319:192-8.

36. Lorin C, Vogeli I, Niggli E. Dystrophic cardiomyopathy: role of TRPV2 channels in stretch-induced cell damage. Cardiovasc Res. 2015;106:153-62.

37. Cox JH, Hussell S, Sondergaard H, Roepstorff K, Bui JV, Deer $\mathrm{JR}$, et al. Antibody-mediated targeting of the Orail calcium channel inhibits T cell function. PLoS One. 2013;8:e82944.

38. Sun H, Luo L, Lal B, Ma X, Chen L, Hann CL, et al. A monoclonal antibody against KCNK9 $\mathrm{K}(+)$ channel extracellular domain inhibits tumour growth and metastasis. Nat Commun. 2016;7:10339.

39. Studzian M, Bartosz G, Pulaski L. Endocytosis of ABCG2 drug transporter caused by binding of 5D3 antibody: trafficking mechanisms and intracellular fate. Biochim Biophys Acta. 2015;1853:1759-71.

40. Shcherbatko A, Foletti D, Poulsen K, Strop P, Zhu G, HasaMoreno A, et al. Modulation of $\mathrm{P} 2 \mathrm{X} 3$ and $\mathrm{P} 2 \mathrm{X} 2 / 3$ receptors by monoclonal antibodies. J Biol Chem. 2016;291:12254-70.
41. Koch SE, Mann A, Jones S, Robbins N, Alkhattabi A, Worley $\mathrm{MC}$, et al. Transient receptor potential vanilloid 2 function regulates cardiac hypertrophy via stretch-induced activation. J Hypertens. 2017;35:602-11.

42. Entin-Meer M, Levy R, Goryainov P, Landa N, Barshack I, Avivi $\mathrm{C}$, et al. The transient receptor potential vanilloid 2 cation channel is abundant in macrophages accumulating at the peri-infarct zone and may enhance their migration capacity towards injured cardiomyocytes following myocardial infarction. PLoS One. 2014;9: e105055.

43. Entin-Meer M, Cohen L, Hertzberg-Bigelman E, Levy R, BenShoshan J, Keren G. TRPV2 knockout mice demonstrate an improved cardiac performance following myocardial infarction due to attenuated activity of peri-infarct macrophages. PLoS One. 2017;12:e177132.

44. Jones S, Mann A, Worley MC, Fulford L, Hall D, Karani R, et al. The role of transient receptor potential vanilloid 2 channel in cardiac aging. Aging Clin Exp Res. 2017;29:863-73.

45. Chan AC, Carter PJ. Therapeutic antibodies for autoimmunity and inflammation. Nat Rev Immunol. 2010;10:301-16.

46. Scott AM, Wolchok JD, Old LJ. Antibody therapy of cancer. Nat Rev Cancer. 2012;12:278-87.

47. Matsumura T, Matsui M, Iwata Y, Asakura M, Saito T, Fujimura $\mathrm{H}$, et al. A pilot study of tranilast for cardiomyopathy of muscular dystrophy. Intern Med. 2018;57:311-8.

48. Moore BJR, Islam B, Ward S, Jackson O, Armitage R, Blackburn $\mathrm{J}$, et al. Repurposing of tranilast for potential neuropathic pain treatment by inhibition of sepiapterin reductase in the $\mathrm{BH} 4$ pathway. ACS Omega. 2019;4: 11960-72. 